\title{
Yoga as a Complementary Therapy for Social Media Generation's Well Being
}

Purva G. Sharma and Gopal Krishna Sharma

\begin{abstract}
Unlike past, preteens and teens today lead a mentally and emotionally charged life along with the exacting physical rigors of their daily life. Apart from sports, academics, parents and peers the mentioned age group is also spending a considerable amount of time in the virtual, digital world of social media connectivity along with its various appendages. Unregulated social media exposure often makes life a tightrope existence for these children and adolescents. Studies have shown that the increasing use of social media and technology is having a negative impact on the physical and mental health of children and teenagers by making them more prone to anxiety, depression, and other psychological disorders, as well as by making them more susceptible to future health problems. In this light of increased stress and health problems with growing social media usage, this paper reviews studies and proposes yoga as a mind-body alternative medicine intervention to improve physical and mental health conditions. It also highlights the efficacy of yoga as a complementary therapy enhancing overall wellbeing of children. After reviewing relevant available literature, we conclude that Yoga has the potential to be a promising complementary therapy for children and adolescents but more efforts are required to find most effective application and implementation methods for the same.
\end{abstract}

Key words: Stress, children, adolescents, social media, yoga, well-being 


\section{Introduction}

Throughout the first 70 years of research, there was a common assumption that adolescence was a time of "storm and stress" (Hall, 1904). Adolescence is the important time in which an individual learns how to deal with the world. It can be a stressful time for children, parents, and adults who work with teens. Children are dealing with the challenges of going through puberty, meeting changing expectations and coping with new feelings every day.

Many children worry about moving from middle school to high school or from school to college, it is a transition that has been particularly stressful for most people (Brooks \& DuBois, 1995). Each of these transitions can present challenges at both the academic performance and psychological well-being front (Seidman, Aber, \& French, in press). While most children meet these challenges successfully and grow into healthy adults, others have a harder time coping with their problems and may experience emotional maladjustment and depression.

In the present era of competition everyone has to prove themselves which pressurizes adolescents to excel in every activity to get an edge and syand out in this cut throat competition.In this context, David Elkind, professor at Tufts University and author of "The Hurried Child: Growing Up Too Fast, Too Soon” (1988)very rightly says, "Our society is compressing childhood more and more to where children are not children for very long. Children are under tremendous pressure to 'be mature' and to grow up”.

With this augmented pressure and "matureness", parent-adolescent conflict tends to increase during this growth period of adolescents, partly due to the parents having high expectations from their children who are not being able to meet their these expectations well. This is so because both the parents being working are engaged in some and the other life-chores of today's' hectic lifestyle leading to a gap in communication and lack of guidance resulting into many youngsters feeling lost and uncared for. This contemporary issue was not the case in the olden days where parents were able to give time to their children and guide them through their developmental stages, or in the collectivistic societies where children are better taken care of, if not by the parents then, by the other family members or the society in general. Chen and Farruggia (2002) have studied this phenomena and have also concluded something on the same lines and that a lack of this parental care in individualistic societies prepares youths for "going it on their own" and develop affection ties with nonfamilial others.

Such studies have proved that when proper caring and sharing is not given by parents the child tries and finds that care and affection outside the home. With the advent of new technologies and media these days it has become very easy to fill in this gap of communication between parents and children by conveniently connecting and communicating with others in the virtual world in just a click.

Social media has connected people more with the others than their own family members and relatives. Especially young generation is compulsively using social media which has increased stress, and has produced anxiety and depression. It has deeply affected their mental health and well-being (Maldonado, 2014), and also has made them further susceptible to more future health problems. Fiona Macrael, the Oxford University expert believes that constant computer and internet use may be causing 'rewiring of the brain', shortening of attention spans, encouraging instant gratification and causing a loss of empathy (2010). This is resulting in various stress related ailments and psychological problems which poses threat and challenges for the physical as well as mental well-being of the school going children. 
In such times, much emphasis has been provided on the physical \& mental wellbeing of children and adolescents to promote overall well-being in our society. Yoga is one such method by which this goal of positive health can be achieved. Yoga plays a significant role in enhancing one's mental health, which is conducive for their effective performance in all aspects of life. Yoga is considered as a mind-body exercise. The underlying premise of Yogic mind-body exercises is that the physiological state of the body may shape emotions, thoughts and attitudes (Monk-Turner \& Turner, 2010) maintaining overall wellbeing. Thus, keeping these negative impacts of social media and stressful life-style on adolescents, the authors in this paper are proposing yoga as a complementary therapy which can be applied and implemented in schools and colleges.

\section{Negative impact of social media on stress and mental-health}

How is our life affected by the use of social media? In India, there are about 118 million active social media users (Gurung, 2015) out of which most are adolescents on social network sites such as Facebook, Twitter etc. This results that students pay less attention to real world and social interaction rather they spend most of their time online. In addition study time is being compromised too and lesser time is spared to family members. The situation leads to lack of exercise resulting in a bad state of health. Other major psychological consequences are internet addiction, Facebook depression, sleep deprivation, insomnia and restlessness.

Rosen (2011) argues that daily overuse of media and technology has a negative impact on the health of all children, pre-teens and teenagers. Overuse of social media and technology make them more prone to anxiety, depression, and other psychological disorders, as well as more susceptible to future health problems. Facebook and other such social networking sites can be distracting and negatively impact academic performance concentration and focus capacity (Junco, 2012). Studies have also found that middle school, high school and college students who checked Facebook at least once during a 15-minute study period achieved lower grades. Krakowsky (2014) concluded that social media is not only a distraction to teenagers addicted to checking news feeds but it leads to psychological and health issues.

A University of Michigan study indicated that Facebook usage in young adults lead to decline in subjective well-being. Moreover, it was also found that as the intensity of use of Facebook increased in young adults the worse they felt moment-to-moment and the less they felt satisfied with their lives (Kross,Verduyn, et al. 2013). Several studies (eg. Valkenburg, Peter \& Schouten, (2006) have also shown that social networking can have detrimental effects on our wellbeing.

The one common bad effect of social media is addiction-the constant checking of Facebook, Twitter, or other social media updates. Research showed that a number of anxiety and personality disorders stem from spending too much time on the Internet. "Social Media Anxiety Disorder", for example, occurs when people become addicted. When technology abusers check their devices very often it triggers the addictionoriented parts of their brains. For kids and teens, this addiction could disrupt other worthwhile activities like schoolwork, reading, sports, etc.

Paediatricians observed that some teens suffer from "Facebook depression". After spending a lot of time on Facebook and other popular social networking sites, some teens become anxious and moody. Also, a vulnerable teen may suffer from depression when he reads great things happening to his friends and isn't doing so well for himself in comparison. Teens, which experience "Facebook depression", usually have trouble with social interactions in general, 
according to the American Academy of Paediatrics (AAP).

Aldridge and Harden (2014) studied regarding trend of "Selfies", which has became popular with the rise of camera phones. It is being seen as potential triggers for mental health conditions and narcissism and it leads people becoming obsessed with their appearance. The Mirror, for example, recently featured a selfie addict who tried to kill himself when he couldn't take a perfect photo. According to Rutledge (2013), "Preoccupation with selfies can be a visible indicator of a young person with a lack of confidence or sense of self that might make one victim of other problems too. Excessive and increasingly provocative 'selfie' is a form of 'acting out,' a common behavioral pattern to get attention."

Social media depression is a phenomenon characterized by the American Academy of Pediatrics (AAP) as the psychological impact that social media websites - such as Facebook and Twitter, as well as gaming sites with virtual worlds, YouTube, and online communities that cause depression and self-esteem issues in people with underlying risk of mental health issues (Fleet, 2013). Several other researches shown that excessive usage of social media has affected mental health, including depression, isolation, insecurity and more recently, FOMO, also known as "Fear Of Missing Out". Fear of missing out is a phenomenon that occurs when you feel pressurized to be doing what everyone else is doing, attend every event, and share every life experience. It can evoke anxiety and cause social media users to question why everyone is "having fun without them." Surveys have found that people feel insecure after using Pinterest because they feel that they aren't crafty or creative enough.

According to Vidyarthi (2011) in the last ten years the average attention span has dropped from 12 minutes to a staggeringly short 5 minutes which is a really drastic change. Two recent studies on teachers' views about the impact of digital media on children's learning by the Pew Research Center's Internet \& American Life Project, and by Common Sense Media indicated that students' constant use of digital technology was hampering their attention spans and ability to persevere in the face of challenging tasks. Nearly three quarters of the 685 public and private K-12 teachers surveyed that usage of entertainment media (including $\mathrm{TV}$, video games, texting and social networking) had hurt all student's attention spans severely or moderate. Likewise, in the Pew online survey, which polled 2,462 middle and high school teachers, $87 \%$ reported that these technologies had created an easily distracted generation with short attention spans, and 64\% said that digital technologies did more to distract students than to help them academically. Research evidences that social networking usage negatively impacts the attention span of youth and adolescents has now brought attention of society to find solutions (Greenfield 2009; Ophir, Nass, \& Wagner, 2009; Wintour 2009).

\section{Effects of yoga on mental health}

Yoga, as an ancient system of exercise, is being used more and more by people of all ages to promote overall health and fitness. There is also a progressive trend towards the use of yoga as a mind-body complementary and alternative medicine intervention to improve specific physical and mental health conditions. Yoga has been recommended as a great supplement to current physical activities at schools because it emphasizes individual abilities rather than competition, making it attractive to all children, including those with physical limitations and lack of involvement in organized sports. Yoga also has the potential to reduce obesity and other health issues.

Since yoga is hailed as a mindfulness exercise (Burke, 2010), it enhances one's self-awareness including breathing, posture, diet, and 
behaviours, and it has the potential to influence the all aspects of personality and health. Yoga reduced adults anxiety (Brown \&Gerbarg, 2005), and relaxed them (Smith, Hancock, Blake-Mortimer, \& Eckert, 2007; Waelde, Thompson, \& Gallagher-Thompson, 2004). Yoga research on children also improved attention and emotional control (Jensen \& Kenny, 2004).

Yoga therapy is defined by the International Association of Yoga Therapists (IAYT) as "the process of empowering individuals to progress toward improved health and well-being through the application of the philosophy and practice of yoga” (Taylor, 2007). It is recognized by the National Institutes of Health (NIH), National Center for Complementary and Alternative Medicine (NCCAM) as a form of CAM in the category of "mind-body" medicine. NCCAM (2010) asserts that mind-body medicine "focuses on the interactions among the brain, mind, body, and behaviour, and on the powerful ways in which emotional, mental, social, spiritual, and behavioral factors can directly affect health.”

Furthermore, "Mind-body medicine typically focuses on intervention strategies that are thought to promote health. It is regarded as a fundamental approach that respects and enhances each person's capacity for selfknowledge and self-care, and it emphasizes techniques that are grounded in this approach. People who exercise yoga frequently report a sense of deep relaxation, calmness and happiness at the end of a yoga session (MonkTurner \& Turner, 2010). Few systematic reviews have shown that yoga has positive effects on depression (Cramer et al., 2012; Ten Damme, 2013; Mehta et al., 2010). It is also effective for relieving stress and anxiety conditions that impact physical and mental health conditions (Long, Huntley, \& Ernst, 2001). Furthermore, positive effects of yoga have been seen on wellbeing and satisfaction with life in some studies (Impett, Daubenmier\& Hirschman, 2006).
A 2001 study in the Indian Journal of Physiology and Pharmacology showed that participants who practiced yoga consistently for 10 months were less anxious and depressed both during and after their months of yoga practice. By improving circulation in the endocrine glands, a consistent yoga practice enhances the functions of hormones that play a primary role in the physiology of depression which results in a reduction of depression and improves overall mood. Controlled studies have demonstrated the beneficial effects of yoga on anxiety states. Regular yoga practice improves functioning of the parasympathetic nervous system that activates the relaxation response.

Studies by Bhushan\& Sinha (2001) and Kumar (2004) showed the effects of Yoga Nidra on stress, anxiety and general well-being on college going students which denoted a significant change where Yoga Nidra had decreased the stress level of the subjects as well as positively increased their general well-being. Another scientific study done by Kumar (2006) on the effect of Yoga Nidra taking Alpha EEG and GSR of college students had shown that a significant change occurred as Yoga Nidra positively increased the Alpha EEG and GSR of the students, which indicated the improvement of their physical and mental health. According to Heather, Eastmen, Muller (2013) a structured Yoga Nidra intervention may help reduce symptoms of stress, depression and worry and improve mindfulness skills in students. Kumar reported that Yoga Nidra positively decreased the blood pressure (both systolic and diastolic) as well as pulse rate, respiration rate, stress, anger and fear.

Novotney (2009) in quoted Stanford University's health psychologist and yoga instructor, Kelly McGonigal, that The evidence is showing that yoga really helps change people at every level, and that is why more clinicians have embraced yoga as a complement to psychotherapy. Yoga is being encouraged as a 
tool that clients can use at their homes to cope with stress and anxieties and emotional wounds.

Gambhir, Prakash (2006) examined the effects of Om-chanting on subjects and concluded that its practice provided positive effect on mental health. Gangaly (2005) also investigated the effect of meditation and Om-chanting, and found improvement in concentration power. Studies conducted by Vicente Pedro (1987) and Bhushan (1998) found significant reduction in the State Trait Anxiety of the subjects due to regular practice of yoga. In another study Malathi et al. (1998) conducted a yoga intervention study on MBBS students and tested them before and after the examination, and found Anxiety reduction in the students at the time of examination. Srivastava et al. (2004) also found significant reduction in MBBS students' anxiety level as a result of yoga practice. Setterlind (1983) found that regular practice of meditation brought a positive change in the well-being of the subjects. Delmonte (1987) suggested that meditation helped in increase of psychological well-being. Malathi et al. (2000) observed a significant improvement in 9 of the 11 factors of subjective well-being in healthy volunteers at the end of 4 months of yoga practice. Further Gopukumar and Hussain Ali (2002) reported that of 40 days meditation practice brought a significant positive change in the subjective well-being of students.

\section{Discussion}

Summary drawn from the aforementioned studies indicated that social media is not only a distraction to teenagers who have become addicted to checking their news feeds, but that it can lead to psychological and health issues as well (Krakowsky (2014). And a number of studies proved Yoga to be an effective practice for overall wellbeing (eg. Cramer et al., 2012; Ten Damme, 2013; Mehta et al., 2010), thus the present study propose that yoga should be implemented as a complementary therapy in schools and colleges. In this regard, Mardesich
(2007) in her article refers to Lynda Meeder, a school counsellor in UK, who while talking about yoga says that, "Kids are so stressed out. They tell me this is the one time they have to relax.” Yoga makes a difference in children and adolescents' life because it helps them calm themselves through yoga practices which further helps them deal with their anger better and resolve conflicts with siblings and peers. She believes that 'Yoga Kids program is an invaluable tool for children.

However, the question of most effectively execution of Yoga in the current education system is yet to be answered. To answer this question, the present study summarized some effective and economical implementation strategies as below.

With the tightening of school budgets, it can be attractive for classroom teachers to deliver yoga curricula, rather than providing physical education teachers on a regular basis. Research showed that enabling classroom teachers to deliver physical activity could be an economic solution to a daunting health crisis faced by our nation's youngsters (Sherman, Tran, \& Alves, 2010). It is natural for classroom teachers to feel intimidated by incorporating yoga into their curriculum after providing them some basic Yoga training. Yoga appears to be simply a stretching activity, but the variety and sequencing of postures coupled with the practice of deep breathing creates an extremely diverse and effective method of enhancing a range of health-related fitness skills.

Experts at "Yoga Tools for School” in Australia have proposed an age group-wise Yoga program for children with the following suggestions:

1. For lower primary kids it can be developed for nurturing of younger children in a fun but engaging way.

2. For upper primary age group children yoga module should focus on energy stabilisation and empower children to 
enhance their own physical and mental awareness.

3. For high school adolescents yoga tools that cultivate awareness, focus and ease should be implemented.

4. Yoga tools allow teens to experience a sense of space around their concerns and provide techniques for redirecting thoughts, calming the nervous system and supporting the transitions of a busy schedule.

Some similar projects are being run in New York City and Westchester County in the United States which offer yoga and mindfulness classes for students and staff development workshops for teachers.

'The School Yoga Project' offers a unique program combining yoga and mindfulness practices in a straight forward manner. Their approach incorporates 5 key elements i.e. Connect Breathe, Move, Focus and Relax in each session. They have further proposed some modules which could be useful for maintaining students' physical and mental health described as following

- Unit-1 could emphasize on creating a safe space, introducing the students to a variety of asanas (postures) and teaching them how to recognize their feelings while establishing a meaningful sense of community and support in the classroom. It is important at this time to teach students that they don't have to participate in anything that hurts or feels uncomfortable. General familiarity with a range of activities is established in this unit so that future units can explore more depth of experience.

- Unit-2 should incorporate building a foundation of confidence and strength in all students and much emphasis should be placed on the physical experiences of yoga, learning more about how our bodies work, and exploring how capable they are. Along with the development of physical strength building inner strength and resilience should be the focus. Students should be introduced to the idea that strength is not only about power, but also about flexibility and balance.

- Unit-3 could focus onto the students' emotional life. By this point they'll be having a good working knowledge of many aspects of the yoga practice, and as the physical movement is becoming more comfortable they may be asked to reflect more on their internal experience. For turning inward this unit could spend time on mindfulness and meditation practices, as well as grounding and restorative yoga poses.

- Unit-4 could finally bring the lessons of the previous units into the larger class community. Working off of the foundation of confidence and strength that have been building throughout the program, the main focus could be on communication, collaboration and building a community of support and encouragement. Students should work together on challenging partner and group activities that allow them opportunities to both support others and be supported.

- Unit-5 would help provide students the opportunity to share what they have learned via student teaching and wrap up the program.

Such structured programmes/ modules could be implemented everywhere with no or very little cost by all dedicated institutes.

\section{Conclusion}

To conclude with, we could say that though today's students are facing tremendous pressure to achieve success within a world that is highly competitive. The situation is often overwhelming and with weakened family ties 
and negative effects of social media and hence, children and adolescents' are under stressed than ever before in human history. Thus, in the present scenario, we are seeing increased cases of depression and anxiety and other mental health problems. To overcome such issues, the study proposed yoga as the best preventive and most economical and widely applicable solution in the education system itself.

The tools of yoga and mindfulness offer proven methods of managing physical, mental and emotional stress. Bringing these practices to the schools, institutes and community organizations is a simple way to make students' lives happier and healthier, increase their capacity to learn effectively, manage their emotions, regulate their own behavior, and achieve personal and academic success. It requires more awareness about the benefits of yoga need to be spread among the general masses and policy making bodies and more yoga programs on the basis of the suggestions above need to be effectively implemented in our schools and colleges for a healthier society.

Purva G. Sharma ${ }^{1}$ and Gopal Krishna Sharma ${ }^{1 *}$

Department of Computer Science, Dev Sanskriti University, Haridwar, India. $\quad{ }^{*}$ Emailgopal.sharma@dsvv.ac.in

\section{References}

Aldrige,G.,Harden,K. (2014). Selfie took two hundred a day- and tried too kill himself when he could,nt take perfect photo.

Bhushan, L. I. (1998). Yogic Lifestyle and Psychological Well-being. Paper presented as S. P. East West Psychology National Award lecture on 4 Jan. at Hyderabad.

Brooks, J.H., \& DuBois, D.L. (1995).Individual and environmental predictors of adjustment during the first year of college.Journal of College Student Development, 36, 347- 360.

Brown, R., \&Gerbarg, P. (2005).SudarshanKria Yogic Breathing in the Treatment of Stress, Anxiety, and Depression: Part II-Clinical Applications and Guidelines. Journal of Alternative and Complementary Medicine, 11, 711-717. http://dx.doi.org/10.1089/acm.2005.11.711

Buchanan, C.M., Eccles, J.S., and Becker, J.B. Are adolescents the victims of raging hormones: Evidence for activational effects of hormones on moods and behaviors at adolescence. Psychological Bulletin (1992) 111:62-107.

Burke, C. (2010). Mindfulness-Based Approaches with Children and Adolescents: A Preliminary Review of Current Research in an Emergent Field. Journal of Child and Family Studies, 19, 133-144. http://dx.doi.org/10.1007/s10826-009-9282-x

Chen, C., \&Farruggia, S. (2002). Culture and adolescent development. In W. J. Lonner, D. L. Dinnel, S. A. Hayes, \& D. N. Sattler (Eds.), Online Readings in Psychology and Culture (Unit 11, Chapter 2), Center for Cross-Cultural Research, Western Washington University, Bellingham, Washington USA.

Fiona Macrael, 2010, Daily Mail 15 September 2010.

Fleet, A. 2013.8 Ways Social Media Negatively Affects Mental Health.

Galinsky,E (2012). Teachers' views of the impact of digital media on children's learning.

Goldberg, I (1998) Diagnostic criteria.Internet Addiction Disorder.

Gopukumar, K., \& Hussain Ali, M. (2002). Meditation - A harbinger of subjective well-being. Journal of Personality and Clinical Studies. 19, 93102.

Gurung, Y. (2015) The latest numbers on web, mobile, and social media in India.

Hall, G. S. (1904). Adolescence: Its psychology and its relation to physiology, anthropology, sociology, 
sex, crime, religion, and education (Vols. I \& II). Englewood Cliffs, NJ: Prentice-Hall.

Heather Eastmen-Muller (2013). Yoga Nidra on college campus: Changes in stress, depression, worry and mindfulness. International journal of yoga therapy-Volume no. 23(2), 2013.

Psych Central. Retrieved on February 24, 2015, from http://psychcentral.com/lib/the-anxiety-of-

facebook/00019448

Mardesich,J (2007) Yoga in schools. Retrieved from http://www.yogajournal.com/article/teach/yoga-inschools/

Monk-Turner, E. \& Turner, C. (2010). Does yoga shape body, mind and spiritual health and happiness: Differences between yoga practitioners and college students.International Journal of Yoga, 3 (2), 48- 54.

National Center for Complementary and Alternative Medicine. What is complementary and alternative medicine?

Neil Vidyarthi on Dec. 14, 2011 retrieved from http://www.adweek.com/socialtimes/attention-spanshave-dropped-from-12-minutes-to-5-seconds-howsocial-media-is-ruining-our-minds-infographic/87484

Ophir, E. Nass, C., \& Wagner, A. (2009).Cognitive control in media multitaskers. Proceedings of the National Academy of Sciences, 106(37)

Paikoff, R.L., and Brooks-Gunn, J. Do parent-child relationships change during puberty? Psychological Bulletin (1991) 110:47-66.

Presentation: "Poke Me: How Social Networks Can Both Help and Harm Our Kids"

Larry D. Rosen, PhD, California State University, Dominguez Hills

Seidman, E., Aber, J. L., \& French, S. (in press). Restructuring the transition to middle/junior high school: A strengths-based approach to the organization of schooling. In K. Maton, C. Schellenbach, B. Leadbeater, \& A. Solarz (Eds.),Promoting strengths-based policies for children, youth, families, and communities.
Washington, DC: American Psychological Association.

Setterlind, S. (1983). Relaxation training in School : Review of research and empirical studies.Goteborg, Sweden : Acta Universities Gothoburgensis.

Sherman, C., Tran, C., \& Alves, Y. (2010). Elementary School Classroom Teacher Delivered Physical Education: Costs, Benefits, and Barriers. The Physical Educator, 67, 2-12.

Smith, C., Hancock, H., Blake-Mortimer, J., \& Eckert, K. (2007).A Randomized Comparative Trial of Yoga and Relaxation to Reduce Stress and Anxiety. Complementary Therapies in Medicine, 15, 77-83.

Taylor MJ.(2007) What is yoga therapy? IAYT offers a definition for the field. Yoga Therapy in Practice.;3(3):3.

Valkenburg, P. M., Peter, J., \& Schouten, A. P. (2006).Friend networking sites and their relationship to adolescents' well-being and social selfesteem.CyberPsychology\&Behavior, 9(5), 584-590.

Vicente Pedro. (1987). Role of Yoga Therapy in Anxiety, Neurosis and Depression. Yoga Mimamsa, XXVI, 1-14.

Waelde, L., Thompson, L., \& Gallagher-Thompson, D. (2004).A Pilot Study of a Yoga and Meditation Intervention for Dementia Caregiver Stress. Journal of Clinical Psychology, 60, 677687.http://dx.doi.org/10.1002/jclp.10259

Wintour, P. (2009). Facebook and Bebo risk of 'infantilising' the human mind. Guardina. 